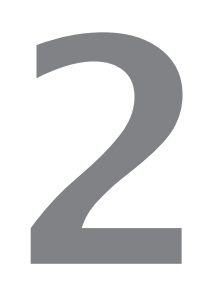

\title{
Tema e relevância
}

Muitas estruturas do mundo da engenharia civil são sensíveis aos efeitos da não-linearidade geométrica. As construções destinadas às telecomunicações, como postes de telefonia móvel celular, são exemplos de estruturas civis cuja influência desses efeitos afetam diretamente a determinação de suas frequências. Para iniciar a compreensão dos aspectos da não-linearidade geométrica na dinâmica das estruturas é imprescindível, para o momento, entender que a matriz de rigidez de estruturas sujeitas a cargas axiais elevadas é diferente da matriz de rigidez elástica. Dessa forma, a introdução de aspectos não-lineares na dinâmica das estruturas, sob determinado contexto, pode ser convenientemente feito por meio do conceito de rigidez geométrica. 
Embora de forma sutil, seu emprego é uma consideração não-linear, já que a rigidez geométrica depende do estado de tensões internas, ou esforços internos, na estrutura, que só se consegue determinar a partir das deformações causadas pelos deslocamentos que ela sofre. Claro que se esses esforços internos forem mantidos constantes a partir daí, estar-se-ia ignorando os deslocamentos adicionais que ocorrem a partir desse estado de deformações inicial. É, pois, uma linearização de um problema não-linear a partir de uma certa configuração que não é a inicial descarregada.

Analisando pelo Método dos Elementos Finitos, Cook (1974) se refere à rigidez geométrica como forças de membrana existentes em barras ou em elementos planos, como placas e cascas. O termo membrana é usado por ele para denotar uma força interna agindo na direção tangente à superfície do elemento. Para investigá-las, Cook (1974) conclui que se faz necessário introduzir uma nova matriz de rigidez, denominada de "matriz de tensões inicias", "matriz de rigidez geométrica" ou "matriz dos coeficientes de estabilidade". Esses nomes derivam de suas aplicações e do fato que independem de propriedades elásticas, sendo função exclusiva da geometria e das forças internas dos elementos, presumidas conhecidas e constantes (forças nodais).

É de especial importância a investigação dos efeitos decorrentes da não-lienaridade geométrica para as estruturas esbeltas submetidas à ação de vento. Um caso de particular interesse, sem perda de generalidade, são os postes usados no sistema de telefonia móvel celular.

O vento não era problema em construções baixas e pesadas de grossas paredes, mas passou a ser, e em medida crescente, quando as construções foram-se tornando mais e mais esbeltas e as estruturas usando cada vez menos material. O perigo de o vento produzir acidentes é particularmente importante para torres de transmissão de energia elétrica, torres de rádio, televisão e microondas, antenas de radar e outras estruturas semelhantes, é o que afirma Blessmann (2001). Os efeitos de ventos sobre postes esbeltos e torres são particularmente enfatizados por Simui; Scalan (1996), Sachs (1972), Kolousek et al (1984) e Navara (1969). 
Acidentes com torres de transmissão elétrica, alguns deles envolvendo a queda de mais de 10 torres consecutivas no Estado de São Paulo, foram relatados por Blessmann (2001). Alem desses acidentes, Blessmann (2001) menciona o estudo feito sobre furacões em Miami em 1950 e relata a destruição completa de 11 torres metálicas de rádio por flambagem individual de barras. A ocorrência de acidentes com postes de telefonia móvel celular são mencionados por Brasil e Silva (2006).

Levando em consideração esses aspectos, é oportuno mencionar que a NBR 8681/03 - Ações e segurança nas estruturas, norma brasileira que fixa os requisitos exigíveis na verificação da segurança das estruturas, recomenda que, no projeto de estruturas, devem ser considerados os estados limites últimos de perda de equilíbrio, global ou parcial, admitida a estrutura como um corpo rígido; e o de instabilidade dinâmica. Quando menciona os estados limites de serviço, a NBR 8681/03, prescreve que devem ser observados, os que possam afetar a sua utilização normal, entre eles o de vibração excessiva. Além da NBR 8681/03, outras duas normas que se relacionam diretamente com o projeto de postes de telecomunicações são as NBR 6118/04 - Projeto de estruturas de concreto armado e a NBR 8800/96 - Projeto e execução de estruturas de aço de edifícios, que fazem restrições quanto à esbeltez dessas estruturas.

Para efeitos deste trabalho, postes são estruturas de barra, alongados e de seção circular ou poligonal circunscrita com grande número de lados. Já as torres são estruturas reticuladas, constituídas por perfis metálicos ou tubos, podendo ser estaiadas ou não.

No Brasil, uma profunda reforma do aparato legal que regulava o setor tornou possível a reestruturação das telecomunicações. O traço fundamental foi a transformação do monopólio público, provedor de serviços de telecomunicações, em um novo sistema de concessão pública a operadores privados, fundado na competição e orientado para o crescimento da universalização dos serviços. Em 1998 o Governo Federal vendeu as 12 holdings criadas a partir da cisão do Sistema Telebrás, representando a transferência à iniciativa privada das Empresas de Telefonia Fixa e de Longa Distância, bem como das Empresas de Telefonia Celular. 
Essa foi uma escolha política e economicamente pragmática, através da qual o Brasil optou por desenvolver a telefonia celular, com intenção de abreviar uma etapa do desenvolvimento.

A privatização do Sistema Telebrás ocorreu no dia 29 de julho 1998 por meio de 12 leilões consecutivos na Bolsa de Valores do Rio de Janeiro, configurando a maior operação de privatização de um bloco de controle já realizada no mundo. ${ }^{1}$ A partir daí foram implantadas em todo o Brasil milhares de estações para transmissão do sinal de telefonia. A implantação foi feita num ritmo explosivo com a instalação de milhares de estações em todo o país. Dada a disparidade de custo entre os sistemas eletrônicos e as obras civis, pouco se investiu na engenharia estrutural envolvida, resultando em projetos e construções realizados com metodologia duvidosa e na herança de uma grande quantidade de problemas estruturais.

Brasil e Silva (2006) afirmam que durante a implantação do sistema de telefonia celular no Brasil mais de 10.000 estruturas de telecomunicações foram projetadas, fabricadas e construídas. Dessas, 2000 eram poste de concreto armado. Como relatam, no início dos anos 90 havia poucas companhias e técnicos para atender à demanda. Companhias especializadas em outros produtos adaptaram sua linha de produção para o mercado das telecomunicações. Nesse contexto, os engenheiros de estruturas, muitos dos quais especializados em outras aplicações, adaptaram seus modelos matemáticos ao projeto das estruturas de telecomunicações. O modelo adotado por muitos deles, continuam Brasil e Silva (2006), estavam baseados em modelos estáticos, nos quais a carga de vento era calculada como carga estática, desconsiderando os efeitos dinâmicos do vento e as características da localidade onde seriam instaladas essas estruturas. Os resultados desse distorcido e caótico processo apareceram em pouco tempo, com as estruturas apresentando uma série de problemas estruturais e com a ocorrência de alguns acidentes.

Os engenheiros de estruturas poderiam encontrar amparo para a manutenção de seus procedimentos nas prescrições da norma brasileira que trata da ação do vento em edificações, pois nela há expressões para o cálculo da frequência que, em alguns casos, lhes

1 Fonte BNDES (http://www.bndes.gov.br) 
dispensariam da obrigação de levar em conta os efeitos dinâmicos da ação de vento. Nessas expressões, a altura da edificação é o fator preponderante de cálculo.

Represada por considerações de ordem ambiental e estética, a instalação indiscriminada de torres, atualmente vive-se uma nova demanda para a análise do aproveitamento das estruturas existentes para aplicação de novas cargas.

As estruturas usadas como suportes do sistema de transmissão do sinal de telefonia são, em boa, parte constituídas apenas de um poste em balanço (Figura 2.1), metálico ou de concreto armado, de análise estrutural enganosamente simples.
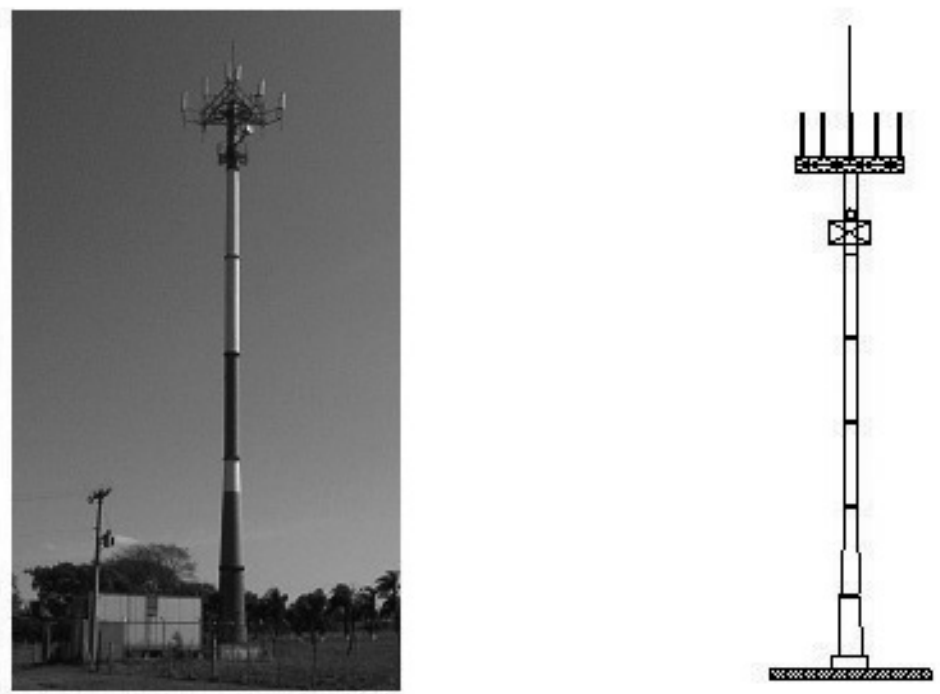

Figura 2.1 - Poste usado no sistema de telefonia celular.

O que deve ser levado em consideração, e por vezes esquecido, é a extraordinária esbelteza desses elementos, que ao engenheiro lhe deveria sugerir, de imediato, a necessidade de considerar a não-linearidade geométrica forçosamente existente. Além disso, o carregamento transversal atuante é o do vento, de características eminentemente dinâmicas e aleatórias, distintas daquelas preconizadas em Normas, quando de naturezas predominantemente estáticas ou dinâmicas determinísticas. Em decorrência da sua elevada esbelteza, essas estruturas estão passíveis de comportamentos diversos dos bá- 
sicos esperados, pois, dependendo do carregamento, ou ainda devido às características próprias das estruturas da realidade, podem ocorrer fenômenos de instabilidade local ou global.

Mazzilli (1979) afirma que, à primeira vista, poderia parecer que a segurança das estruturas esbeltas estivesse perfeitamente salvaguardada desde que os materiais estruturais, nos cálculos mecânicos, não revelassem esgotamento de suas capacidades resistentes. No entanto, essas estruturas, como afirma, são sensíveis a pequenas perturbações mecânicas. Para as estruturas de telecomunicações o vento é o fator determinante de projeto.

As ações exercidas pelo vento tornam-se particularmente importantes em estruturas esbeltas e de grande altura. Quanto mais esbeltas, mais sensíveis às ações dinâmicas do vento (BLESSMANN, 1989).

A verificação dos esforços provenientes da ação do vento apresenta dificuldades à análise de estruturas devido à grande variabilidade e à aleatoriedade do carregamento. Calcular os deslocamentos e esforços internos provocados por carregamento de vento não é tarefa das mais fáceis porque as cargas mudam constantemente ao longo do tempo. Por essa razão, usualmente se adota uma simplificação importante de cálculo com a adoção de carregamentos estáticos equivalentes, considerando-se uma velocidade característica do vento.

Para muitas estruturas esse é um critério válido, onde as vibrações produzidas pelo vento podem ser desprezadas e os cálculos das tensões e deformação podem ser realizados como se o esforço do vento agisse sobre a estrutura como uma força estática, sem a necessidade de observar seus atributos dinâmicos. No entanto, para estruturas esbeltas e flexíveis, e no caso específico dos postes de telefonia móvel celular, o vento, incidindo na estrutura, nas antenas e nos demais dispositivos construtivos (Figura 2.2), introduz efeitos dinâmicos importantes, que não devem ser desprezados. A turbulência do vento causa uma carga flutuante que acarreta vibração na estrutura, daí decorre a necessidade da verificação da reposta dinâmica.

Um problema de dinâmica estrutural difere de seu equivalente estático em dois importantes aspectos. A primeira diferença a ser 
notada, por definição, é a característica de variação temporal do problema dinâmico, devido ao fato de que o carregamento e a reposta variam com o tempo. É evidente que um problema dinâmico não possui uma única solução, como é o caso de um problema estático. A análise dinâmica deve, ao contrário, estabelecer uma sucessão de soluções para todos os instantes. Assim, a análise dinâmica é claramente mais complexa que a análise estática.
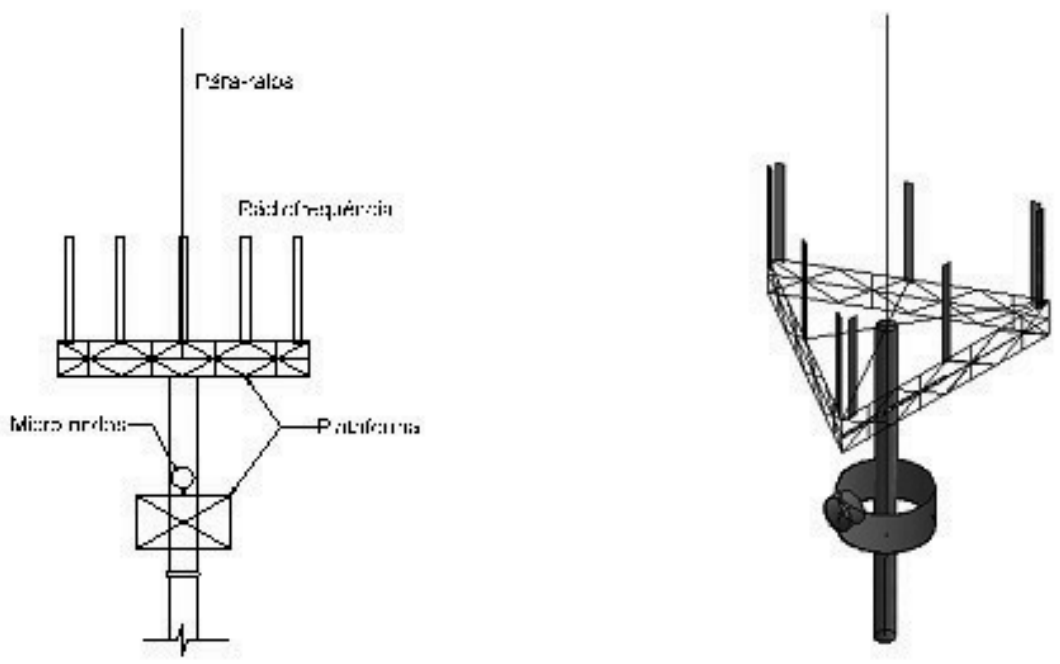

\section{Figura 2.2 - Antenas e anteparos típicos de um poste de telefonia.}

Existe, no entanto, um segundo aspecto que diferencia fundamentalmente problemas estáticos e dinâmicos. Trata-se do surgimento de forças de inércia, associadas às acelerações, e forças de dissipação, usualmente associadas às velocidades, além, é claro, das forças restauradoras. Consequentemente, a solução do problema dinâmico difere consideravelmente de seu equivalente estático, sendo necessário o desenvolvimento de soluções para as equações diferenciais no tempo.

Como expõe Ravara (1969), para realizar a análise dinâmica de uma estrutura é preciso quantificar as solicitações aplicadas; definir um modelo estrutural; definir um modelo matemático que represente, sob os pontos de vista de deformabilidade e absorção de energia, o 
comportamento da estrutura; e aplicar as teorias de vibrações mecânicas ao estudo do comportamento do modelo matemático. Uma vez definido o modelo matemático, como por exemplo, um oscilador com número discreto ou infinito de graus de liberdade e quantificadas as solicitações dinâmicas que atuam sobre ele, constitui um problema da Teoria das Vibrações determinar a resposta da estrutura, ou seja, os deslocamentos, velocidades e acelerações que se desenvolvem nos seus elementos.

Os graus de liberdade representam o número escolhido de funções temporais que, uma vez conhecidas, determinam univocamente o movimento de cada elemento estrutural. Uma estrutura contínua tem infinitos graus de liberdade.

A solução de problemas de vibração para sistemas contínuos pode ser obtida empregando-se técnicas de discretização ou por métodos variacionais. Como afirmam Géradin e Rixan (1998), sistemas contínuos são casos limites de sistemas discretos.

Embora os graus de liberdade representem o número de parâmetros necessários para definir a posição de qualquer parte do sistema, para muitas estruturas a carga dinâmica na direção do vento pode ser calculada com razoável precisão admitindo-se que a estrutura tenha um único grau de liberdade e apenas a componente da ação flutuante na direção do vento necessita ser levada em conta na verificação da vibração considerada (DYBEYE \& HANSEN, 1996).

Para estruturas com modos de vibração, cujas primeiras frequências encontram-se abaixo de $1 \mathrm{~Hz}$, os efeitos dinâmicos do vento tornam-se importantes e a consideração desses efeitos como estáticos ou de natureza determinística é uma aproximação por demais grosseira. A importância da consideração da ação do vento nas estruturas é destacada por Durbey, C. \& Hansen, O S. (1996) quando afirmam que estruturas com rigidez moderada podem vibrar de diferentes formas quando sujeitas à ação do vento, e salientam que, quando se trata de estruturas esbeltas, o efeito dinâmico produzido pela ação do vento pode, ainda, entrar em ressonância com a estrutura.

Navara (1969) destaca a relevância da consideração da estabilidade aerodinâmica para construções metálicas e de concreto armado de grande altura, como torres auto-resistente destinadas a telecomu- 
nicações, tendo em vista que, além da frequência dessas estruturas situarem-se normalmente abaixo de $1 \mathrm{~Hz}$, são fracamente amortecidas e, em geral, são muito expostas ao vento.

$\mathrm{O}$ vento age conjuntamente com a força normal proveniente do peso próprio da estrutura e das cargas em serviço. Na presença do esforço axial a estrutura modificada sua rigidez e, consequentemente, a maneira de como responde aos estímulos do vento, isso significa dizer que modelos lineares não conseguem descrever precisamente o comportamento estrutural.

A norma brasileira que orienta o cálculo de edificações submetidas à ação do vento é a NBR 6123/88 - Forças devidas ao vento em edificações. Nela há três maneiras de se considerar os efeitos produzidos pelo vento, para fins de cálculo. Todas os tratam como uma carga estática equivalente à ação real, dinâmica, do vento (BLESSMANN, 1989).

A opção dada ao engenheiro de escolher entre uma ou outra forma de calcular está relacionada à frequência do modo fundamental de vibração e à altura da edificação.

No primeiro modelo, a influência da resposta flutuante é levada em conta por meio do Fator de Rajada para o cálculo da velocidade característica do vento, porém sem considerar as características dinâmicas do problema em estudo, e admitindo que a estrutura não entre em ressonância com o vento.

Os dois outros modelos tratam especificamente da resposta dinâmica na direção do vento médio, e estão estipulados no capítulo 9 da NBR 6123/88. Neles se admite que a flutuações do vento se dêem nas frequências naturais da estrutura. Esses processos se iniciam com a obtenção das frequências naturais de vibração das edificações, necessárias à determinação dos correspondentes coeficientes de amplificação dinâmica. Portanto, o cálculo da frequência natural das estruturas é o fator primordial para o cálculo dos efeitos dinâmicos devidos à turbulência atmosférica.

As sugestões contidas na NBR 6123/88 para a determinação da frequência do primeiro modo de alguns tipos de estruturas não se aplicam confortavelmente às estruturas de telecomunicações, o que pode conduzir a equivocadas interpretações. 
Neste trabalho, desenvolveu-se uma expressão para o cálculo da frequência fundamental das estruturas de telecomunicações, ou de qualquer outra estrutura em balanço que possa ser modelada como elemento de barra, que leva em conta a não-linearidade geométrica, importante para os sistemas esbeltos, e na qual pode ser incluída a não-linearidade do material, caso exista. 